\title{
Longitudinal associations between body mass index and serum carotenoids: the CARDIA study
}

\author{
Lene Frost Andersen ${ }^{1,2}$, David R Jacobs Jr ${ }^{1,2}$, Myron D. Gross ${ }^{3}$, Pamela J. Schreiner ${ }^{2}$, O. Dale Williams ${ }^{4}$ \\ and Duk-Hee Lee ${ }^{5}$ \\ ${ }^{1}$ Department of Nutrition, University of Oslo, Norway \\ ${ }^{2}$ Division of Epidemiology, School of Public Health, University of Minnesota, Minneapolis USA \\ ${ }^{3}$ Department of Laboratory Medicine and Pathology, School of Medicine, University of Minnesota, Minneapolis USA \\ ${ }^{4}$ Division of Preventive Medicine, School of Medicine, University of Alabama, Birmingham, Alabama USA \\ ${ }^{5}$ Department of Preventive Medicine, School of Medicine, Kyungpook, National University, Daegu, South Korea
}

(Received 24 May 2005 - Revised 13 September 2005 - Accepted 29 September 2005)

\begin{abstract}
Cross-sectional studies report an inverse association between BMI and serum carotenoid concentration. The present study examined the prospective association between BMI and the serum concentration of five carotenoids in the Coronary Artery Risk Development in Young Adults (CARDIA) study. Serum carotenoids ( $\alpha$-carotene, $\beta$-carotene, $\beta$-cryptoxanthin, zeaxanthin/lutein, lycopene), BMI, dietary intake, physical activity and dietary supplement use were measured at years 0 and 7 in 3071 black and white male and female participants, who were either persistent smokers or non-smokers. Among non-smokers, year 0 BMI predicted year 7 serum carotenoid levels: obese subjects $\left(\mathrm{BMI} \geq 30 \mathrm{~kg} / \mathrm{m}^{2}\right)$ had an average concentration of the sum of four carotenoids $(\alpha$-carotene $+\beta$-carotene + zeaxanthin/lutein $+\beta$-cryptoxanthin) that was $22 \%$ lower than the concentration among subjects with a BMI of less than $22 \mathrm{~kg} / \mathrm{m}^{2}$. In contrast, the sum of carotenoids among smokers was only $6 \%$ lower. Relationships between BMI and serum lycopene were weak. The change from year 0 to year 7 in serum carotenoids, except for lycopene, was inversely associated with the change in BMI among non-smokers but not among smokers. Parallel findings were observed for BMI and serum $\gamma$-glutamyl transferase level. In summary, the observation that BMI predicted the evolution of serum carotenoids during a 7-year follow-up among young non-smoking adults is consistent with the hypothesis that carotenoids are decreased in protecting against oxidative stress generated by adipose tissue, while smokers maintain a minimal level of serum carotenoids independent of adiposity. The results for lycopene were, however, discordant from those of the other carotenoids.
\end{abstract}

BMI: CARDIA study: Carotenoids

Several epidemiological studies have reported an independent and inverse association between BMI and carotenoid concentrations in blood even when adjusted for other factors associated with carotenoid concentration, such as intake of fruit and vegetables, fat, fibre, alcohol, supplement use, smoking, gender and lipid concentrations (Brady et al. 1996; Yeum et al. 1998; Neuhouser et al. 2001; Wallstrom et al. 2001; Ford et al. 2002). This association may be important in the development of chronic diseases related to BMI as high concentrations of blood constituents that have antioxidant properties, such as carotenoids, have been prospectively shown to be associated with a low incidence of CVD and several cancers (Comstock et al. 1992; Gey, 1993; Ito et al. 2003; Sesso et al. 2004).

The relationship between BMI and carotenoid concentration may reflect three pathways. First, BMI and serum carotenoids may be correlated because of dietary and other lifestyle factors that affect them both. Second, serum carotenoids are partially fat soluble and are spread throughout both blood and an enlarged mass of fat tissue; they may be reduced in obesity because relatively fewer are located in the blood (Brady et al. 1996; Wallstrom et al. 2001). Third, adipose tissue may generate oxidative stress (Davi et al. 2002; Higdon \& Frei, 2003; Morrow, 2003), and the carotenoids may be reduced because of defending against this stress. In support of this 'stress defence' hypothesis are earlier Coronary Artery Risk Development in Young Adults (CARDIA) findings of a positive association between BMI and $\gamma$-glutamyl transferase (GGT), both cross-sectionally (Lee et al. 2003) and longitudinally (Lee et al. 2004b), and an inverse association between GGT and serum carotenoids (Lee et al. 2004b).

With the increase in obesity observed worldwide (DarntonHill et al. 2004), it is important to have a more complete understanding of the association between carotenoids and BMI. Most of the previous studies investigating the association between BMI and serum carotenoid concentrations have been cross-sectional. The purpose of the present study was to examine, in a prospective fashion, the association 
between BMI and the serum concentration of five carotenoids in the large and biracial CARDIA study, expanding on our earlier work (Lee et al. 2003, 2004a,b). Our primary hypothesis was that BMI would independently predict future carotenoid level.

\section{Subjects and methods}

The Young Adult Longitudinal Trends in Antioxidants study measured serum antioxidant concentrations in frozen samples as an ancillary study to the CARDIA study. CARDIA is a longitudinal, multicentre epidemiological study of lifestyle and other factors on the evolution of CHD risk factors during young adulthood; no interventions are included in the study. Study design, recruitment of participants and methods have been described elsewhere (Friedman et al. 1988). In 1985-6, 5115 black and white men and women aged 18-30 years were recruited and examined at four field centres in the USA: Birmingham, AL; Chicago, IL; Minneapolis, MN; Oakland, CA. Participants were re-examined at 2, 5, 7, 10 and 15 years after baseline, with re-examination rates among surviving cohort members of $91 \%, 86 \%, 81 \%, 79 \%$ and $74 \%$, respectively.

Standard questionnaires were used to maintain consistency in the assessment of demographic and behavioural information across CARDIA examination visits. Sex, race, date of birth and cigarette smoking were determined by structured interview or by self-administered questionnaire. A physical activity score was derived from the CARDIA Physical Activity History, a simplified version of the Minnesota Leisure Time Physical Activity Questionnaire (Jacobs et al. 1989). Body weight with light clothing was measured to the nearest $0.2 \mathrm{~kg}$, and height without shoes was measured to the nearest $0.5 \mathrm{~cm}$. BMI was computed as weight divided by height squared $\left(\mathrm{kg} / \mathrm{m}^{2}\right)$.

The CARDIA Diet History, an interviewer-administered quantitative food-frequency questionnaire identified 1609 distinct food items at years 0 and 7. Intake of energy, fibre, alcohol, total fruit (including fruit juice) and total vegetables (including vegetable juice) was computed from the Diet History (Liu et al. 1994).

Blood samples were drawn after an overnight fast by venepuncture into vacutainers. After plasma or serum separation, aliquots were stored at $-70^{\circ} \mathrm{C}$ until shipped on dry ice to a central laboratory. Year 0 and 7 plasma lipids were measured at the University of Washington Northwest Lipid Research Clinic Laboratory, USA. Total plasma cholesterol levels were determined using enzymatic procedures. HDL-cholesterol was determined after precipitation of LDL-containing lipoproteins with dextran sulphate $/ \mathrm{MgCl}_{2}$ (Warnick et al. 1982). LDL-cholesterol was calculated using the Friedewald equation (Friedewald et al. 1972); the few individuals with triacylglycerol levels above $4.52 \mathrm{mmol} / \mathrm{l}(400 \mathrm{mg} / \mathrm{dl})$ were excluded from this calculation.

Serum obtained at CARDIA years 0 and 7 was used to assay the carotenoids $\alpha$ - and $\beta$-carotene, lycopene, zeaxanthin/ lutein, and $\beta$-cryptoxanthin in year 8 at the Molecular Epidemiology and Biomarker Research Laboratory, University of Minnesota, USA. The carotenoids were measured by an HPLC-based assay based on a modification of the method of Bieri et al. (1985) with calibration as described by Craft et al. (1988) and sample-handling as described by Gross et al. (1995). The primary modification was a simultaneous detection of tocopherols and carotenoids. Calibration was performed against pure compounds (Hoffman-LaRoche, Basel, Switzerland; Sigma Chemical Co., St Louis, MO, USA). Quality-control procedures included the routine analysis of plasma and serum control pools containing high and low concentrations of each analyte. In addition, the laboratory routinely analysed National Institutes of Standards and Technology reference sera and was a participant in the National Institutes of Standards and Technology Fat-Soluble Vitamin Quality Assurance Group. The coefficients of variation were less than $10 \%$ for all analytes and control pools. We have previously shown that the intraclass correlation coefficients (ratio of between-person variance to between- plus within-person variance) were 0.93 for $\alpha$-carotene, 0.98 for $\beta$-carotene, 0.73 for lutein/zeaxanthin, 0.97 for $\beta$-cryptoxanthin and 0.73 for lycopene (Iribarren et al. 1997).

Serum GGT was measured at year 0 using a SMAC II continuous-flow analyser (Technicon Instruments Corp. Tarrytown, NY, USA) at American Bio-science Laboratories (now Smith-Kline Beecham King of Prussia, Pennsylvania, USA), and at year 10 colorimetrically with nitroanilide methodology on a Roche Cobas Indianapolis, Indiana, USA. Mira Plus chemistry instrument at Linco Research Inc St Louis, Missouri, USA. As previously described (Lee et al. 2004b), we corrected for a lack of comparability between year 0 and year 10 measurements using the formula: recalibrated year 0 GGT values $=2.7618+(1.9004 \times$ original year 0 values).

A supplement user was defined as any person consuming $\beta$-carotene or vitamins $\mathrm{A}, \mathrm{E}$ or $\mathrm{C}$ in excess of his or her intake from foods alone. In the present paper a supplement user was a person who used one or more of these supplements at either year 0 or year 7 , and a non-supplement user was a person who did not use supplements at both years 0 and 7 .

For some of the analyses, BMI was classified into BMI $<22 \mathrm{~kg} / \mathrm{m}^{2}, 22-24.9 \mathrm{~kg} / \mathrm{m}^{2}, 25-29.9 \mathrm{~kg} / \mathrm{m}^{2}$ (overweight) and $\geq 30 \mathrm{~kg} / \mathrm{m}^{2}$ (obese); the lowest cut-off point is approximately the median of those with normal weight.

This paper includes non-pregnant participants who attended both the year 0 and 7 examinations and for whom we had both BMI and serum carotenoid assessments, and who were either smokers at both year 0 and year 7 or non-smokers at both exams. We excluded pregnant women, including seven at year 0 and sixty-two at year 7. A total of 1029 of the CARDIA study participants did not return for the year 7 follow-up examination. BMI was missing in seventeen of all participants at year 0 and in ninety-nine of those who returned at year 7. All five serum carotenoid assessments were missing in 305 of all participants at year 0 and in 321 of those who returned at year 7. A total of forty-three of the participants attending both examinations were missing smoking information at either examination, and 459 had variable smoking patterns. Many of these exclusions overlapped, with the result that 3174 people were available for analysis. After excluding people who had missing covariate data in the fully adjusted model described below under statistical analysis, the final sample was reduced from 3174 to 3071. For the analyses including year 10 GGT, the sample was reduced to 2730 . 


\section{Statistical analysis}

We examined associations between serum carotenoids and BMI in several ways:

1. the cross-sectional association between year 0 serum carotenoids (dependent variables) and year 0 BMI (independent variable), and year 7 serum carotenoids (dependent variables) and year 7 BMI (independent variable);

2. the longitudinal association between year 7 serum carotenoids (dependent variables) and year 0 BMI (independent variable);

3. the longitudinal association between the changes in serum carotenoids (year 7 - year 0; dependent variable) and changes in BMI (year 7 - year 0; independent variables).

Results were presented for long-term smokers and long-term non-smokers separately as there was a significant interaction of smoking and BMI with each serum carotenoid except lycopene in both cross-sectional and longitudinal analyses.

Adjustment for potential confounding was analysed by linear regression. Two models were run. The first included minimal adjustment for field centre, race, sex and year 0 values of age (years), plasma cholesterol and HDL-cholesterol (we additionally adjusted for changes in total cholesterol and HDL-cholesterol between year 0 and 7 in Tables 3 and 4 later). We adjusted for lipids because several of the carotenoids are lipophilic (Gross et al. 2003).

The second fully adjusted model also included possibly confounding behaviours at year 0 : alcohol consumption ( $\mathrm{ml} / \mathrm{d})$; physical activity (continuous); energy intake (kcal); vegetable and fruit intake (eating occasions/week); and vitamin supplement use at either year 0 or year 7 . Replacement of the dichotomous supplement use covariate with the contin uous amounts of each of four supplements at both years did not greatly alter the results. In an earlier study, supplement use, alcohol intake and physical activity were significantly correlated with the serum concentrations of carotenoids in the CARDIA study (Lee et al. 2004b). The fully adjusted model also included year 0 carotenoids in the model that predicted year 7 carotenoids from year 0 BMI, thereby estimating the evolution of carotenoids over the 7-year period.

The age-, race- and sex-adjusted correlation of the year 0 physical activity score with the year 0 sum of four serum carotenoids was $0 \cdot 10$, whereas the corresponding correlation for serum lycopene was $-0 \cdot 01$. The age-, race- and sex-adjusted correlation of the year 0 total intake of fresh fruit, juice and vegetables with the year 0 sum of the serum concentrations of four carotenoids was $r=0 \cdot 22$, whereas the intake of these foods was unrelated to year 0 serum lycopene $(r=-0 \cdot 06)$.

We considered alternative adjustment for diet in sensitivity analyses, given the complexity of the association of diet with serum carotenoids. Specifically, starting with 195 food groups, we used a stepwise series of regressions to identify the foods explaining the most between-person variance of the sum of four serum carotenoids. A priori hypotheses in these regressions were that carotenoid-containing fruits and vegetables would relate positively to the levels of circulating carotenoids, as would other plant foods that more generally reduce oxidative stress. Red meat and deep-fried foods were hypothesised a priori to increase oxidative stress and therefore to reduce circulating carotenoids. With these hypotheses in mind, and adjusting for total energy intake, we performed regressions of specific food subgroups within each major food group (vegetables, fruit, grains, dairy, fish, red meat, poultry, fats and oils, legumes, nuts, and non-alcoholic beverages). We dropped food subgroups that were not significant, and then ran a combined regression across food groups of statistically significant food subgroups. Finally, we dropped nonsignificant food subgroups from the combined regression. A dietary score including twenty-eight food groups (prominently featuring carotenoid-containing fruit and vegetables) was developed from this procedure; this had a high correlation with the sum of four serum carotenoids $(r=0 \cdot 5)$. Similarly, we devised a dietary score that included eleven food groups (prominently featuring tomato products) and had a correlation with serum lycopene of $r=0 \cdot 26$. Adjustment for these two dietary scores did not alter the findings presented; these more complex analyses are not shown.

We examined associations between BMI and GGT by looking at the association between year 10 GGT (dependent variable) and year 0 BMI (independent variable), holding year 0 GGT constant. In the adjusted model, we included meat in addition to the fully adjusted model described above, as meat has been shown to be associated with GGT (Lee et al. 2004c).

In the present paper, only the fully adjusted models are presented. There were only small differences between the minimally and fully adjusted models. Statistical analyses were performed with SAS software, version 8.2 (SAS Institute, Inc, Cary, NC, USA).

\section{Results}

\section{Cross-sectional and tracking}

At baseline, the distribution of gender was almost equal between non-smokers and smokers. No differences were observed between smokers and non-smokers in relation to age and BMI. Non-smokers reported a significantly higher physical activity and had significantly higher serum concentrations $(17-100 \%)$ of $\alpha$-carotene, $\beta$-carotene, $\beta$-cryptoxanthin and zeaxanthin/lutein compared with smokers (Table 1). Moreover, the non-smokers had a significantly higher percentage of white participants and supplement users compared with the smokers.

The serum carotenoids are mostly intercorrelated. Year 0 age-, race- and sex-adjusted correlations are: $\alpha$-carotene and $\beta$-carotene, $r=0.72 ; \beta$-cryptoxanthin with $\alpha$-carotene, $\beta$-carotene and zeaxanthin/lutein, $r=0.40,0.42$ and 0.43 , respectively; zeaxanthin/lutein with $\alpha$-carotene, $\beta$-carotene and lycopene, $r=0.29,0.30$ and 0.30 , respectively. Serum lycopene shows little correlation with $\alpha$-carotene, $\beta$-carotene and cryptoxanthin $(r=-0.04,0.06$ and 0.08 , respectively); although small, these correlations achieve statistical significance given that $n$ 3071). We present associations with BMI for the sum of four carotenoids to emphasise this correlation structure and the similarity of associations described below between each of $\alpha$-carotene, $\beta$-carotene, $\beta$-cryptoxanthin and zeaxanthin/lutein, and BMI, whereas lycopene followed a distinct pattern. This sum also simplifies the statistical discussion. The variables of interest also display strong tracking 
Table 1. Characteristics of the sample by smoking at year 0

(Means and standard deviations, or percentages)

\begin{tabular}{|c|c|c|c|c|c|c|}
\hline & \multicolumn{2}{|c|}{$\begin{array}{l}\text { Non-smokers } \\
\quad(n 2310)\end{array}$} & \multicolumn{2}{|c|}{ Smokers ( $n 761)$} & \multicolumn{2}{|l|}{$P$-value } \\
\hline & Mean & SD & Mean & SD & Mean & SD \\
\hline Age (years) & $25 \cdot 0$ & $3 \cdot 6$ & $25 \cdot 3$ & 3.7 & 0.09 & \\
\hline Male $(\%)$ & 45 & & 48 & & 0.15 & \\
\hline White race (\%) & 56 & & 42 & & $<0.001$ & \\
\hline Physical activity (exercise units) & 432 & 301 & 404 & 295 & 0.03 & \\
\hline BMI $\left(\mathrm{kg} / \mathrm{m}^{2}\right)$ & $24 \cdot 4$ & 4.8 & 24.5 & $5 \cdot 1$ & 0.55 & \\
\hline Supplement user (\%) & 52 & & 40 & & $<0.001$ & \\
\hline \multicolumn{7}{|l|}{ Dietary intake } \\
\hline Energy (kcal) & 2700 & 1432 & 3404 & 1904 & $<0.001$ & \\
\hline Alcohol $(g)$ & 8.6 & $14 \cdot 8$ & $20 \cdot 3$ & 30.8 & $<0.001$ & \\
\hline Crude fibre $(\mathrm{g})$ & 5.7 & 3.5 & 5.9 & 3.7 & 0.17 & \\
\hline$\beta$-Carotene $(\mu \mathrm{g})$ & 4540 & 6263 & 3991 & 4484 & 0.009 & \\
\hline Vitamin E (mg) & $20 \cdot 6$ & 69.5 & $16 \cdot 1$ & $24 \cdot 2$ & 0.008 & \\
\hline Vitamin C (mg) & 277 & 384 & 237 & 245 & $<0.001$ & \\
\hline Fruit (times/week) & $8 \cdot 3$ & $7 \cdot 7$ & 6.9 & $7 \cdot 6$ & $<0.001$ & \\
\hline Vegetable (times/week) & $17 \cdot 9$ & $12 \cdot 1$ & $17 \cdot 7$ & 11.4 & 0.65 & \\
\hline \multicolumn{7}{|l|}{ Serum concentration $(\mu \mathrm{g} / \mathrm{dl})$} \\
\hline$\alpha$-Carotene & $3 \cdot 2$ & $4 \cdot 1$ & 1.6 & $1 \cdot 6$ & $<0.001$ & \\
\hline$\beta$-Carotene & $17 \cdot 3$ & $15 \cdot 3$ & $10 \cdot 7$ & $7 \cdot 9$ & $<0.001$ & \\
\hline$\beta$-Cryptoxanthin & $9 \cdot 3$ & $6 \cdot 0$ & $6 \cdot 4$ & $3 \cdot 8$ & $<0.001$ & \\
\hline Zeaxanthin/lutein & $19 \cdot 2$ & 8.9 & $16 \cdot 4$ & 8.5 & $<0.001$ & \\
\hline Lycopene & $29 \cdot 6$ & $14 \cdot 2$ & $30 \cdot 2$ & 14.9 & 0.30 & \\
\hline
\end{tabular}

correlations between year 0 and year 7 values, namely 0.87 for BMI and 0.45-0.62 for the five carotenoids. GGT correlation between year 0 and 10 was $0 \cdot 61$.

In cross-sectional analyses restricted to year 0 data, serum concentrations of carotenoids showed significant inverse associations with BMI. Among long-term non-smokers, obese subjects had 24-37\% lower carotenoid concentrations than were seen among subjects with a BMI of less than
$22 \mathrm{~kg} / \mathrm{m}^{2}$, except for serum lycopene, for which the difference was only $9 \%$ (Table 2). Among smokers, the differences between obese subjects and subjects with a BMI of less than $22 \mathrm{~kg} / \mathrm{m}^{2}$, although statistically significant, were generally smaller $(14-24 \%)$, except for serum $\alpha$-carotene, for which the difference was $39 \%$. Cross-sectional analyses restricted to year 7 data showed the same pattern (data not shown).

Table 2. Adjusted $\dagger$ means and their standard errors of year 0 serum carotenoids by classification of year $0 \mathrm{BMI}^{*}$

\begin{tabular}{|c|c|c|c|c|c|c|c|c|c|c|}
\hline & \multicolumn{10}{|c|}{ BMI category } \\
\hline & \multicolumn{2}{|c|}{$\begin{array}{c}<22 \cdot 0 \mathrm{~kg} / \mathrm{m}^{2} \\
\text { (low) }\end{array}$} & \multicolumn{2}{|c|}{$\begin{array}{c}22 \cdot 0-24.9 \mathrm{~kg} / \mathrm{m}^{2} \\
\text { (normal) }\end{array}$} & \multicolumn{2}{|c|}{$\begin{array}{c}25 \cdot 0-29.9 \mathrm{~kg} / \mathrm{m}^{2} \\
\text { (overweight) }\end{array}$} & \multicolumn{2}{|c|}{$\begin{array}{c}\geq 30.0 \mathrm{~kg} / \mathrm{m}^{2} \\
\text { (obese) }\end{array}$} & \multirow[b]{2}{*}{$P_{\text {trend }}$} & \multirow{2}{*}{$\begin{array}{l}\% \text { Difference } \\
\text { low - obese }\end{array}$} \\
\hline & Mean & SE & Mean & SE & Mean & SE & Mean & SE & & \\
\hline Non-smokers & \multicolumn{2}{|c|}{$n 794$} & \multicolumn{2}{|c|}{$n 711$} & \multicolumn{2}{|c|}{$n 568$} & \multicolumn{2}{|c|}{ n 237} & & \\
\hline$\alpha$-Carotene $(\mu \mathrm{g} / \mathrm{l})$ & $3 \cdot 8$ & 0.14 & $3 \cdot 3$ & $0 \cdot 14$ & $2 \cdot 7$ & $0 \cdot 16$ & $2 \cdot 4$ & 0.25 & $<0.0001$ & 37 \\
\hline$\beta$-Carotene $(\mu \mathrm{g} / \mathrm{l})$ & $19 \cdot 9$ & 0.53 & $17 \cdot 2$ & 0.54 & $15 \cdot 4$ & 0.61 & $13 \cdot 4$ & 0.98 & $<0.0001$ & 33 \\
\hline$\beta$-Cryptoxanthin ( $\mu \mathrm{g} / \mathrm{l})$ & $10 \cdot 2$ & 0.20 & $9 \cdot 6$ & 0.21 & 8.7 & $0 \cdot 24$ & $7 \cdot 1$ & 0.38 & $<0.0001$ & 30 \\
\hline Zeaxanthin/lutein $(\mu \mathrm{g} / \mathrm{l})$ & $20 \cdot 7$ & 0.30 & $19 \cdot 2$ & 0.31 & $18 \cdot 5$ & 0.35 & $15 \cdot 8$ & 0.56 & $<0.0001$ & 24 \\
\hline Sum of carotenoids $(\mu \mathrm{g} / \mathrm{l}) \ddagger$ & $54 \cdot 6$ & 0.86 & $49 \cdot 3$ & 0.88 & $45 \cdot 3$ & 0.99 & $38 \cdot 6$ & 1.60 & $<0.0001$ & 29 \\
\hline Lycopene $(\mu \mathrm{g} / \mathrm{l})$ & 30.5 & 0.48 & $29 \cdot 2$ & 0.49 & 29.5 & 0.56 & $27 \cdot 8$ & 0.89 & 0.006 & 9 \\
\hline Smokers & \multicolumn{2}{|c|}{$n 256$} & \multicolumn{2}{|c|}{$n 251$} & \multicolumn{2}{|c|}{$n 156$} & \multicolumn{2}{|c|}{$n 98$} & & \\
\hline$\alpha$-Carotene $(\mu \mathrm{g} / \mathrm{l})$ & $1 \cdot 8$ & 0.09 & $1 \cdot 6$ & 0.09 & 1.5 & 0.11 & $1 \cdot 1$ & 0.15 & 0.001 & 39 \\
\hline$\beta$-Carotene $(\mu \mathrm{g} / \mathrm{l})$ & $11 \cdot 8$ & 0.48 & $10 \cdot 7$ & 0.48 & $10 \cdot 2$ & 0.60 & $9 \cdot 0$ & 0.79 & 0.002 & 24 \\
\hline$\beta$-Cryptoxanthin $(\mu \mathrm{g} / \mathrm{l})$ & $6 \cdot 8$ & 0.23 & $6 \cdot 5$ & 0.22 & 5.9 & 0.28 & $5 \cdot 7$ & 0.37 & 0.01 & 16 \\
\hline Zeaxanthin/lutein $(\mu \mathrm{g} / \mathrm{l})$ & $17 \cdot 6$ & 0.51 & $16 \cdot 0$ & 0.50 & $15 \cdot 8$ & 0.64 & $15 \cdot 2$ & 0.83 & 0.004 & 14 \\
\hline Sum of carotenoids $(\mu \mathrm{g} / \mathrm{l}) \dagger$ & $38 \cdot 0$ & 1.02 & $34 \cdot 8$ & 1.01 & 33.4 & $1 \cdot 28$ & $31 \cdot 1$ & 1.68 & 0.0002 & 18 \\
\hline Lycopene $(\mu \mathrm{g} / \mathrm{l})$ & $31 \cdot 8$ & 0.90 & $30 \cdot 8$ & 0.89 & $28 \cdot 7$ & $1 \cdot 13$ & $27 \cdot 0$ & 1.48 & 0.006 & 15 \\
\hline
\end{tabular}

${ }^{*} P$-values for interaction with smoking and BMI: 0.03 with $\alpha$-carotene, 0.016 with $\beta$-carotene, 0.003 with $\beta$-cryptoxanthin, 0.12 with zeaxanthin/lutein, 0.002 with sum of carotenoids and 0.20 with lycopene.

† Adjustment was made by linear regression. Adjustment included field centre, race, sex, and year 0 age, alcohol consumption, physical activity, energy intake, fruit intake, vegetable intake and plasma concentration of cholesterol and HDL-cholesterol plus year 0 or 7 supplement use.

$\ddagger$ Sum of $\alpha$-carotene, $\beta$-carotene, $\beta$-cryptoxanthin and zeaxanthin/lutein. 
Table 3. Adjusted $\dagger$ means and their standard errors of year 7 serum carotenoids by classification of year $0 \mathrm{BMI}^{*}$

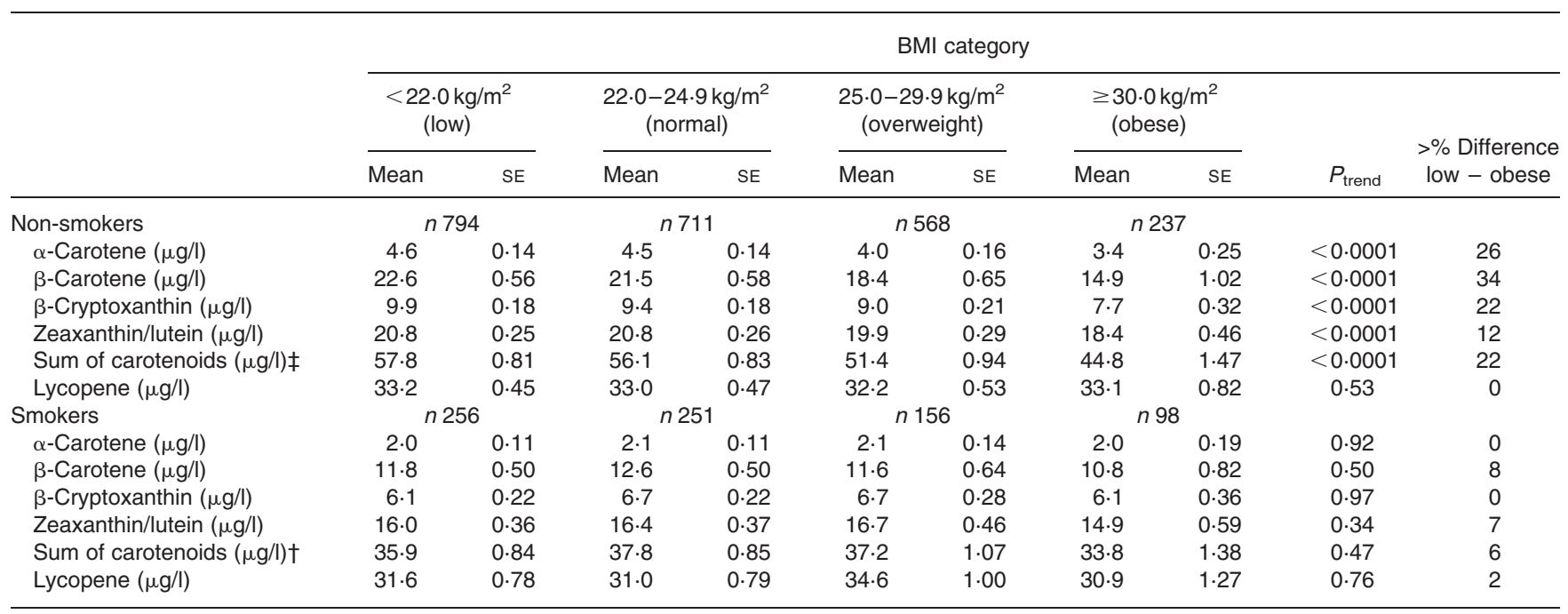

${ }^{*} P$-values for interaction with smoking and BMI: 0.03 with $\alpha$-carotene, 0.001 with $\beta$-carotene, 0.001 with $\beta$-cryptoxanthin, 0.002 with zeaxanthin/lutein, $<0.001$ with sum of carotenoids and 0.56 with lycopene.

†Adjustment was made by linear regression. Adjustment included field centre, race, sex, and year 0 age, alcohol consumption, physical activity, energy intake, vegetable intake, fruit intake, plasma carotenoids year 0 (e.g. $\alpha$-carotene in its row, $\beta$-carotene in its row, etc.) and plasma concentration of cholesterol and HDL-cholesterol plus year 0 and 7 supplement use.

¥ Sum of $\alpha$-carotene, $\beta$-carotene, $\beta$-cryptoxanthin and zeaxanthin/lutein.

\section{Prospective}

Longitudinal associations predicting the evolution of carotenoids showed the same general pattern as observed in the crosssectional analysis. The year 0 BMI strongly and inversely predicted the year 7 serum concentrations of carotenoids among non-smokers. Obese subjects at year 0 had 12-34\% lower carotenoid concentrations at year 7 than subjects with a BMI below $22 \mathrm{~kg} / \mathrm{m}^{2}$ at year 0 , except for lycopene, for which no differences were observed. No associations were observed among the smokers (Table 3). These findings indicate that the cross-sectional inverse association between year $0 \mathrm{BMI}$ and the year 0 sum of carotenoids (Table 2) evolved during 7 years of follow-up. No such evolution was seen when the variables were reversed; that is, the year 0 sum of carotenoids did not predict the year $7 \mathrm{BMI}$, holding the year 0 BMI constant (data not shown).

The change from year 0 to year 7 in the serum concentrations of carotenoids except for lycopene showed significant inverse associations with changes in BMI among non-smokers, but no association was found among smokers except for serum $\beta$-carotene and the sum of carotenoids (Table 4).

\section{Race interaction}

In the cross-sectional analyses, there was no interaction of gender and BMI (that is, BMI-carotenoid relations were similar in both sexes), but there was a significant interaction of race and BMI with each serum carotenoid except lycopene. A significant interaction between race and BMI was observed for serum $\alpha$-carotene, $\beta$-carotene and $\beta$-cryptoxanthin in the longitudinal analyses. In the analysis of the data separately for black and white participants, qualitatively similar associations to those presented in Tables 2 and 3 were observed in both groups, but the carotenoid concentrations except for lycopene were generally lower and the size of the association was weaker for the black compared with the white participants.

\section{$\gamma$-Glutamyl transferase}

We assessed the extent to which BMI at year 0 was associated with year 10 serum GGT, holding year 0 GGT constant (Table 5). Year 0 BMI strongly and inversely predicted year 10 serum GGT among non-smokers, indicating an evolution of the previously reported (Lee et al. 2003) cross-sectional association between BMI and GGT during 10 years of follow-up. Among smokers, no association between year 0 BMI and year 10 GGT was observed, but GGT levels were considerably higher among smokers than among non-smokers at every BMI level. Baseline GGT did not predict the evolution of BMI during follow-up (data not shown).

\section{Discussion}

The present study indicated that a strong inverse relationship exists between BMI and all measured serum carotenoids, with the exception of lycopene, among non-smokers, both cross-sectionally and longitudinally.

Several studies have reported inverse associations between carotenoid concentrations and BMI, but most of these studies have looked at the associations cross-sectionally, and several have examined only a single carotenoid (Zhu et al. 1997; Rock et al. 1999, 2002; Neuhouser et al. 2001; van Kappel et al. 2001; Wallstrom et al. 2001; Ford et al. 2002). In a 3year follow-up study among fifty-six American women with breast cancer who received advice to increase their fruit and vegetable intake, a marginally significant inverse relationship between changes in BMI and changes in plasma lutein, cryptoxanthin and lycopene $(P<0.09)$ was found; the magnitude of 
Table 4. Adjusted $\dagger$ means and their standard errors of changes in serum carotenoids (year 7 - year 0 ) by quintiles (Q1-Q5) of changes in BMI $(\text { year } 7 \text { - year } 0)^{*}$

\begin{tabular}{|c|c|c|c|c|c|c|c|c|c|c|c|}
\hline & \multicolumn{2}{|c|}{$\begin{array}{c}\mathrm{Q} 1 \\
(-22 \cdot 2-<0 \cdot 1 \\
\left.\mathrm{kg} / \mathrm{m}^{2}\right)\end{array}$} & \multicolumn{2}{|c|}{$\begin{array}{c}\mathrm{Q} 2 \\
(0 \cdot 1-<1.2 \\
\left.\mathrm{kg} / \mathrm{m}^{2}\right)\end{array}$} & \multicolumn{2}{|c|}{$\begin{array}{c}\text { Q3 } \\
(1 \cdot 2-<2 \cdot 3 \\
\left.\mathrm{kg} / \mathrm{m}^{2}\right)\end{array}$} & \multicolumn{2}{|c|}{$\begin{array}{c}\text { Q4 } \\
(2 \cdot 3-<4 \cdot 0 \\
\left.\mathrm{kg} / \mathrm{m}^{2}\right)\end{array}$} & \multicolumn{2}{|c|}{$\begin{array}{c}\text { Q5 } \\
(4 \cdot 0-15 \cdot 8 \\
\left.\mathrm{kg} / \mathrm{m}^{2}\right)\end{array}$} & \multirow[b]{2}{*}{$P_{\text {trend }}$} \\
\hline & Mean & SE & Mean & SE & Mean & SE & Mean & SE & Mean & SE & \\
\hline \multicolumn{12}{|l|}{ Non-smokers ( $n$ 2310) } \\
\hline$\alpha$-Carotene $(\mu \mathrm{g} / \mathrm{l})$ & 1.5 & 0.21 & 1.4 & 0.20 & 1.0 & $0 \cdot 20$ & 1.0 & 0.20 & 0.4 & 0.21 & $<0.0001$ \\
\hline$\beta$-Carotene $(\mu \mathrm{g} / \mathrm{l})$ & $6 \cdot 3$ & 0.87 & 4.2 & 0.83 & $2 \cdot 7$ & 0.80 & $2 \cdot 8$ & 0.82 & 0.2 & 0.85 & $<0.0001$ \\
\hline$\beta$-Cryptoxanthin ( $\mu \mathrm{g} / \mathrm{l})$ & 0.9 & 0.29 & 0.1 & 0.27 & 0.1 & 0.27 & -0.6 & 0.27 & -0.5 & 0.28 & 0.02 \\
\hline Zeaxanthin/lutein $(\mu \mathrm{g} / \mathrm{l})$ & $2 \cdot 1$ & 0.38 & $1 \cdot 1$ & 0.36 & 1.3 & 0.35 & 0.8 & 0.36 & 0.4 & 0.37 & 0.005 \\
\hline Sum of carotenoids $(\mu \mathrm{g} / \mathrm{l}) \dagger$ & $10 \cdot 8$ & 1.23 & 6.8 & $1 \cdot 17$ & 5.0 & $1 \cdot 14$ & 4.0 & $1 \cdot 16$ & 0.4 & 1.21 & $<0.0001$ \\
\hline \multirow[t]{2}{*}{ Lycopene $(\mu \mathrm{g} / \mathrm{l})$} & 1.9 & 0.71 & 3.5 & 0.67 & $4 \cdot 0$ & 0.65 & $3 \cdot 6$ & 0.66 & $3 \cdot 4$ & 0.69 & 0.77 \\
\hline & \multicolumn{2}{|c|}{$\begin{array}{c}\mathrm{Q1} \\
(-10 \cdot 1-<0.1 \\
\left.\mathrm{kg} / \mathrm{m}^{2}\right)\end{array}$} & \multicolumn{2}{|c|}{$\begin{array}{c}\text { Q2 } \\
(0 \cdot 1-<1 \cdot 2 \\
\left.\mathrm{kg} / \mathrm{m}^{2}\right)\end{array}$} & \multicolumn{2}{|c|}{$\begin{array}{c}\mathrm{Q} 3 \\
(1 \cdot 2-<2 \cdot 3 \\
\left.\mathrm{kg} / \mathrm{m}^{2}\right)\end{array}$} & \multicolumn{2}{|c|}{$\begin{array}{c}\text { Q4 } \\
(2 \cdot 3-<4 \cdot 0 \\
\left.\mathrm{kg} / \mathrm{m}^{2}\right)\end{array}$} & \multicolumn{2}{|c|}{$\begin{array}{c}\text { Q5 } \\
(4 \cdot 0-14 \cdot 8 \\
\left.\mathrm{kg} / \mathrm{m}^{2}\right)\end{array}$} & \\
\hline \multicolumn{12}{|l|}{ Smokers ( $n 761)$} \\
\hline$\alpha$-Carotene $(\mu \mathrm{g} / \mathrm{l})$ & 0.4 & 0.15 & 0.6 & $0 \cdot 15$ & 0.6 & $0 \cdot 16$ & 0.2 & 0.16 & 0.4 & $0 \cdot 17$ & 0.59 \\
\hline$\beta$-Carotene $(\mu \mathrm{g} / \mathrm{l})$ & $2 \cdot 9$ & 0.66 & $1 \cdot 2$ & 0.68 & 1.3 & 0.69 & 0.7 & 0.69 & -0.6 & 0.74 & 0.0002 \\
\hline$\beta$-Cryptoxanthin $(\mu \mathrm{g} / \mathrm{l})$ & 0.4 & 0.32 & -0.9 & 0.33 & 0.3 & 0.34 & -0.1 & 0.34 & 0.5 & 0.36 & 0.47 \\
\hline Zeaxanthin/lutein $(\mu \mathrm{g} / \mathrm{l})$ & 0.1 & 0.56 & $-1 \cdot 0$ & 0.57 & -0.2 & 0.58 & 0.5 & 0.59 & -0.7 & 0.62 & 0.41 \\
\hline Sum of carotenoids $(\mu \mathrm{g} / \mathrm{l}) \ddagger$ & 3.7 & $1 \cdot 19$ & -0.1 & 1.23 & 1.9 & 1.25 & $1 \cdot 3$ & 1.25 & -0.4 & 1.33 & 0.02 \\
\hline Lycopene $(\mu \mathrm{g} / \mathrm{l})$ & 1.7 & $1 \cdot 13$ & 0.8 & $1 \cdot 16$ & $3 \cdot 2$ & $1 \cdot 18$ & 1.4 & $1 \cdot 18$ & 1.4 & 1.26 & 0.90 \\
\hline
\end{tabular}

${ }^{*} P$-values for interaction smoking and BMI: 0.02 for $\alpha$ carotene, 0.13 for $\beta$-carotene, 0.07 for $\beta$-cryptoxanthin, 0.06 for zeaxanthin/lutein, 0.01 for sum of carotenoids and 0.95 for lycopene.

† Adjustment made done by linear regression. Adjustment included field centre, race, sex, and year 0 age, alcohol consumption, physical activity, fruit and vegetable intake and plasma concentration of cholesterol and HDL-cholesterol plus year 0 and 7 supplement use.

$\ddagger$ Sum of $\alpha$-carotene, $\beta$-carotene, $\beta$-cryptoxanthin, and zeaxanthin/lutein.

Table 5. Adjusted† means and their standard errors of year 10 serum $\gamma$-glutamyl transferase (GGT) by classification of year 0 BMI

\begin{tabular}{|c|c|c|c|c|c|c|}
\hline & \multicolumn{4}{|c|}{ BMI category } & \multirow[b]{2}{*}{$P_{\text {trend }}$} & \multirow[b]{2}{*}{$\begin{array}{l}\% \text { Difference } \\
\text { low - obese }\end{array}$} \\
\hline & $\begin{array}{l}<22.0 \mathrm{~kg} / \mathrm{m}^{2} \\
\quad(\text { low })\end{array}$ & $\begin{array}{c}22 \cdot 0-24.9 \mathrm{~kg} / \mathrm{m}^{2} \\
\text { (normal) }\end{array}$ & $\begin{array}{c}25.0-29.9 \mathrm{~kg} / \mathrm{m}^{2} \\
\text { (overweight) }\end{array}$ & $\begin{array}{c}\geq 30.0 \mathrm{~kg} / \mathrm{m}^{2} \\
\text { (obese) }\end{array}$ & & \\
\hline \multicolumn{7}{|l|}{ Year 0 BMI } \\
\hline Non-smokers & $n 722$ & $n 637$ & n 514 & $n 200$ & & \\
\hline GGT $(\mu \mathrm{g} / \mathrm{l})$ & $21.3 \quad 0.66$ & $22.7 \quad 0.68$ & $25.2 \quad 0.77$ & $26.5 \quad 1.27$ & 0.0006 & 24 \\
\hline Smokers & $n 212$ & $n 226$ & $n 131$ & $n 88$ & & \\
\hline GGT $(\mu \mathrm{g} / \mathrm{l})$ & $39.9 \quad 3.77$ & $38.2 \quad 3.57$ & $36.5 \quad 4.67$ & $\begin{array}{lr}38.0 & 6.00 \\
P \text { for interaction }\end{array}$ & $\begin{array}{l}0.39 \\
0.001\end{array}$ & -5 \\
\hline
\end{tabular}

†Adjustment was made by linear regression. Adjustment included field centre, race, sex, and year 0 age, alcohol consumption, physical activity, energy intake, meat intake, vegetable intake, fruit intake, serum GGT year 0 and plasma concentration of cholesterol and HDL-cholesterol and triacylglycerols, plus year 0 and 7.

the relationship was not stated (McEligot et al. 1999). No such relation was observed for plasma $\alpha$ - and $\beta$-carotene. Serum lycopene showed little relation to BMI, as has also been observed by others (Brady et al. 1996; Zhu et al. 1997; Neuhouser et al. 2001; van Kappel et al. 2001; Ford et al. 2002).

At least three reasons for the different behaviour of lycopene compared with other carotenoids exist. Lycopene concentration responds differently to fruit and vegetable intake than does that of other carotenoids; its response is almost specific to the intake of tomato products (Smith-Warner et al. 2000; Brevik et al. 2004). In the present study, serum lycopene concentrations were only weakly related to fruit and vegetable intake (partial correlation coefficients adjusted for sex, race, field centre and energy intake: $r=-0.09$ and -0.04 , respectively). Moreover, serum lycopene levels may reflect a different lifestyle compared with other carotenoids: in our study, for example, lycopene level was almost unrelated to smoking. Finally, some have suggested that the association between serum carotenoids and BMI results from adipose tissue acting as a reservoir that actively takes up lipoproteinassociated carotenoids (Brady et al. 1996; Wallstrom et al. 2001). In individuals with a higher fat mass, a larger proportion of the newly absorbed carotenoids would enter this reservoir, with the result that fewer of the total body carotenoids would exist in the serum. A small controlled study ( $n$ 31) by Zhu et al. (1997) suggested that fat-free mass might also serve as a dynamic reservoir that actively takes up carotenoids from plasma. Lycopene is highly fat-soluble and may easily disperse through adipose tissue as well as blood. Blood values may therefore be proportionately less 
influenced by the intake of lycopene than are those of other carotenoids. We cannot rule out the possibility that this mechanism plays a role for other carotenoids.

Oxidative stress might also explain how an increased BMI might cause a decrease in carotenoid levels (Higdon \& Frei, 2003; Keaney et al. 2003; Morrow, 2003; Suzuki et al. 2003). Oxidative stress, measured mainly by urinary F2-isoprostanes, has been positively associated with BMI (Davi et al. 2002; Keaney et al. 2003; Morrow, 2003; Suzuki et al. 2003), and carotenoid concentrations may be reduced with increasing BMI owing to their use in defence against this oxidative stress (Lasheras et al. 2002). In the present study, serum GGT, which has been asserted to be a marker of oxidative stress (Lee et al., 2004a), was measured at year 10. A positive association was observed between year 10 serum GGT and year 0 BMI, holding year 0 GGT constant, among non-smokers but not among smokers. However, the considerably higher GGT levels among smokers than among non-smokers correspond to the considerably lower sum of carotenoids among smokers than among non-smokers, both these phenomena occurring at every BMI level. The data are consistent with the idea that the oxidative stress caused by smoking is so large that any association of BMI with carotenoids or GGT among smokers is masked.

Another explanation could be that BMI may be reduced as a consequence of the consumption of specific foods, diet generally or physical activity at the same time as these lifestyle factors elevate serum carotenoid levels. Although diet and physical activity were closely related to the values for serum carotenoids, except lycopene, little association was found in this study between BMI and fruit and vegetable intake or physical activity. Our ability to assess this hypothesis fully is compromised by difficulty in reliably assessing lifestyle. The failure of this adjustment to explain the relation could be the result of high within-person variation in both the diet and the physical activity measures relative to the sum of serum carotenoids or BMI.

Smoking causes oxidative stress, against which serum carotenoids are thought to defend (Morrow et al. 1995; Kelly, 2002; Dietrich et al. 2003). In the present study, we found lower levels of serum carotenoids except for lycopene at all levels of BMI among smokers compared with non-smokers. This has been observed in several other studies (Stryker et al. 1988; Ross et al. 1995; Marangon et al. 1998; Dietrich et al. 2003). At the same time, smoking is associated with reduced fruit and vegetable intake, physical activity and increased alcohol consumption, factors associated with reduced carotenoid levels. We do not, however, know what aspect of smoking might limit the relationship between BMI and serum carotenoids. It may be that, under enough oxidative stress, obese smokers induce antioxidant enzymes such as superoxide dismutase or catalase to maintain a minimum carotenoid level.

In summary, these results showed that the strong inverse association between BMI and serum carotenoids, except lycopene, observed by others cross-sectionally also exists over a 7year follow-up in the CARDIA study among non-smokers but not among smokers.

\section{Acknowledgements}

This study was supported in part by US National Heart, Lung, and Blood Institute contracts N01-HC-48 047,
N01-HC-48 048, N01-HC-48 049, N01-HC-48 050 and N01HC-95 095 (CARDIA), and R01-HL053560-08 (Young Adult Longitudinal Trends in Antioxidants).

\section{References}

Bieri J, Brown ED \& Smith JCJ (1985) Determination of individual carotenoids in human plasma by high performance chromatography. J Liq Chromatogr 8, 473-484.

Brady WE, Mares-Perlman JA, Bowen P \& Stacewicz-Sapuntzakis M (1996) Human serum carotenoid concentrations are related to physiologic and lifestyle factors. $J$ Nutr 126, 129-137.

Brevik A, Andersen LF, Karlsen A, Trygg KU, Blomhoff R \& Drevon CA (2004) Six carotenoids in plasma used to assess recommended intake of fruits and vegetables in a controlled feeding study. Eur J Clin Nutr 58, 1166-1173.

Comstock GW, Bush TL \& Helzlsouer K (1992) Serum retinol, betacarotene, vitamin E, and selenium as related to subsequent cancer of specific sites. Am J Epidemiol 135, 115-121.

Craft NE, Brown ED \& Smith JC Jr (1988) Effects of storage and handling conditions on concentrations of individual carotenoids, retinol, and tocopherol in plasma. Clin Chem 34, 44-48.

Darnton-Hill I, Nishida C \& James WP (2004) A life course approach to diet, nutrition and the prevention of chronic diseases. Public Health Nutr 7, 101-121.

Davi G, Guagnano MT, Ciabattoni G, Basili S, Falco A, Marinopiccoli M, Nutini M, Sensi S \& Patrono C (2002) Platelet activation in obese women: role of inflammation and oxidant stress. JAMA $\mathbf{2 8 8}$, 2008-2014.

Dietrich M, Block G, Norkus EP, Hudes M, Traber MG, Cross CE \& Packer L (2003) Smoking and exposure to environmental tobacco smoke decrease some plasma antioxidants and increase gammatocopherol in vivo after adjustment for dietary antioxidant intakes. Am J Clin Nutr 77, 160-166.

Ford ES, Gillespie C, Ballew C, Sowell A \& Mannino DM (2002) Serum carotenoid concentrations in US children and adolescents. Am J Clin Nutr 76, 818-827.

Friedewald WT, Levy RI \& Fredrickson DS (1972) Estimation of the concentration of low-density lipoprotein cholesterol in plasma, without use of the preparative ultracentrifuge. Clin Chem 18, 499-502.

Friedman GD, Cutter GR, Donahue RP, Hughes GH, Hulley SB, Jacobs DR Jr, Liu K \& Savage PJ (1988) CARDIA: study design, recruitment, and some characteristics of the examined subjects. J Clin Epidemiol 41, 1105-1116.

Gey KF (1993) Prospects for the prevention of free radical disease, regarding cancer and cardiovascular disease. $\mathrm{Br}$ Med Bull 49, 679-699.

Gross M, Yu X, Hannan P, Prouty C \& Jacobs DR Jr (2003) Lipid standardization of serum fat-soluble antioxidant concentrations: the YALTA study. Am J Clin Nutr 77, 458-466.

Gross MD, Prouty CB \& Jacobs DR Jr (1995) Stability of carotenoids and alpha-tocopherol during blood collection and processing procedures. Clin Chem 41, 943-944.

Higdon JV \& Frei B (2003) Obesity and oxidative stress: a direct link to CVD?" Arterioscler Thromb Vasc Biol 23, 365-367.

Iribarren C, Folsom AR, Jacobs D Jr, Gross M, Belcher JD \& Eckfeldt JH for the ARIC investigators (1997) Association of serum vitamin levels, LDL susceptibility to oxidation and autoantibodies against MDA-LDL with carotid atherosclerosis. Arterioscler Thromb Vasc Biol 17, 1171-1177.

Ito Y, Wakai K, Suzuki K, et al. (2003) Serum carotenoids and mortality from lung cancer: a case-control study nested in the Japan Collaborative Cohort (JACC) study. Cancer Sci 94, 57-63.

Jacobs D Jr, Hahn LP, Haskell WL, Pirie P \& Sidney S (1989) Validity and reliability of a short physical activity history: CARDIA 
and the Minnesota Heart Health Program. J Cardiopulm Rehabil 9, $448-459$.

Keaney JF Jr, Larson MG, Vasan RS, Wilson PW, Lipinska I, Corey D, Massaro JM, Sutherland P, Vita JA \& Benjamin EJ (2003) Obesity and systemic oxidative stress: clinical correlates of oxidative stress in the Framingham Study. Arterioscler Thromb Vasc Biol 23, 434-439.

Kelly G (2002) The interaction of cigarette smoking and antioxidants. 1. Diet and Carotenoids. Altern Med Rev 7, 370-388.

Lasheras C, Huerta JM, Gonzalez S, Brana AF, Patterson AM \& Fernandez S (2002) Independent and interactive association of blood antioxidants and oxidative damage in elderly people. Free Radic Res 36, 875-882.

Lee DH, Blomhoff R \& Jacobs D Jr (2004a) Is serum gamma glutamyltransferase a marker of oxidative stress?" Free Radic Res 38, $535-539$.

Lee DH, Gross MD \& Jacobs DR Jr (2004) Association of serum carotenoids and tocopherols with gamma-glutamyltransferase: the Cardiovascular Risk Development in Young Adults (CARDIA) Study. Clin Chem 50, 582-588.

Lee DH, Jacobs DR Jr, Gross M, Kiefe CI, Roseman J, Lewis CE \& Steffes M (2003) Gamma-glutamyltransferase is a predictor of incident diabetes and hypertension: the Coronary Artery Risk Development in Young Adults (CARDIA) Study. Clin Chem 49, $1358-1366$.

Lee DH, Steffen LM \& Jacobs DR Jr (2004) Association between serum gamma-glutamyltransferase and dietary factors: the Coronary Artery Risk Development in Young Adults (CARDIA) Study. Am J Clin Nutr 79, 600-605.

Liu K, Slattery M, Jacobs D Jr, et al. (1994) A study of the reliability and comparative validity of the cardia dietary history. Ethn Dis $\mathbf{4}$, $15-27$.

McEligot AJ, Rock CL, Flatt SW, Newman V, Faerber S \& Pierce JP (1999) Plasma carotenoids are biomarkers of long-term high vegetable intake in women with breast cancer. J Nutr 129, 2258-2263.

Marangon K, Herbeth B, Lecomte E, Paul-Dauphin A, Grolier P, Chancerelle Y, Artur Y \& Siest G (1998) Diet, antioxidant status, and smoking habits in French men. Am J Clin Nutr 67, 231-239.

Morrow JD (2003) Is oxidant stress a connection between obesity and atherosclerosis?" Arterioscler Thromb Vasc Biol 23, 368-370.

Morrow JD, Frei B, Longmire AW, Gaziano JM, Lynch SM, Shyr Y, Strauss WE, Oates JA \& Roberts LJ (1995) Increase in circulating products of lipid peroxidation (F2-isoprostanes) in smokers. Smoking as a cause of oxidative damage. N Engl J Med 332, 1198-1203.

Neuhouser ML, Rock CL, Eldridge AL, Kristal AR, Patterson RE, Cooper DA, Neumark-Sztainer D, Cheskin LJ \& Thornquist MD (2001) Serum concentrations of retinol, alpha-tocopherol and the carotenoids are influenced by diet, race and obesity in a sample of healthy adolescents. $J$ Nutr 131, 2184-2191.

Rock CL, Thornquist MD, Kristal AR, Patterson RE, Cooper DA, Neuhouser ML, Neumark-Sztainer D \& Cheskin LJ (1999) Demographic, dietary and lifestyle factors differentially explain variability in serum carotenoids and fat-soluble vitamins: baseline results from the sentinel site of the Olestra Post-Marketing Surveillance Study. J Nutr 129, 855-864.

Rock CL, Thornquist MD, Neuhouser ML, Kristal AR, NeumarkSztainer D, Cooper DA, Patterson RE \& Cheskin LJ (2002) Diet and lifestyle correlates of lutein in the blood and diet. J Nutr 132, 525S-530S.

Ross MA, Crosley LK, Brown KM, Duthie SJ, Collins AC, Arthur JR \& Duthie GG (1995) Plasma concentrations of carotenoids and antioxidant vitamins in Scottish males: influences of smoking. Eur J Clin Nutr 49, 861-865.

Sesso HD, Buring JE, Norkus EP \& Gaziano JM (2004) Plasma lycopene, other carotenoids, and retinol and the risk of cardiovascular disease in women. Am J Clin Nutr 79, 47-53.

Smith-Warner SA, Elmer PJ, Tharp TM, Fosdick L, Randall B, Gross M, Wood J \& Potter JD (2000) Increasing vegetable and fruit intake: randomized intervention and monitoring in an at-risk population. Cancer Epidemiol Biomarkers Prev 9, 307-311.

Stryker WS, Kaplan LA, Stein EA, Stampfer MJ, Sober A \& Willett WC (1988) The relation of diet, cigarette smoking, and alcohol consumption to plasma beta-carotene and alpha-tocopherol levels. Am J Epidemiol 127, 283-296.

Suzuki K, Ito Y, Ochiai J, et al. (2003) Relationship between obesity and serum markers of oxidative stress and inflammation in Japanese. Asian Pac J Cancer Prev 4, 259-266.

van Kappel AL, Steghens JP, Zeleniuch-Jacquotte A, Chajes V, Toniolo P \& Riboli E (2001) Serum carotenoids as biomarkers of fruit and vegetable consumption in the New York Women's Health Study. Public Health Nutr 4, 829-835.

Wallstrom P, Wirfalt E, Lahmann PH, Gullberg B, Janzon L \& Berglund G (2001) Serum concentrations of beta-carotene and alpha-tocopherol are associated with diet, smoking, and general and central adiposity. Am J Clin Nut 73, 777-785.

Warnick GR, Benderson J \& Albers JJ (1982) Dextran sulfate-Mg ${ }^{2+}$ precipitation procedure for quantitation of high-density-lipoprotein cholesterol. Clin Chem 28, 1379-1388.

Yeum KJ, Booth SL, Roubenoff R \& Russell RM (1998) Plasma carotenoid concentrations are inversely correlated with fat mass in older women. J Nutr Health Aging 2, 79-83.

Zhu YI, Hsieh WC, Parker RS, Herraiz LA, Haas JD, Swanson JE \& Roe DA (1997) Evidence of a role for fat-free body mass in modulation of plasma carotenoid concentrations in older men: studies with hydrodensitometry. $J$ Nutr 127, 321-326. 